\title{
Modeling Performance Appraisal using Soft Computing and ANN
}

\author{
Sanket Ghorpade \\ Dept. of Computer Engineering, \\ Late G. N. S. C.O. E.,
}

\author{
J. V. Shinde \\ Dept. of Computer Engineering, \\ Late G. N. S. C.O. E.,
}

\begin{abstract}
Evaluation of the quality of an individual's performance in an organization is modeled using a formal management system known as Performance. Performance Appraisal is based on quantitative as well as qualitative parameters. Adherence to performance evaluation parameters such as a specific work schedule, interpersonal skills and innovation, communication skills and team collaboration that is ability to coordinate well with other associates or employees could be some of the factors or performance measures that govern the performance appraisal result. Evaluating some of the factors involve vagueness, uncertainty and imprecision as they are based on judgment making ability of the reviewer. A timesheet can be termed as a process or method for recording the amount of a time utilized by the employee on each job. If multiple such timesheet are integrated, then some of the evaluation parameters could be calculated using soft computing techniques and which help in decision making from available data and experience to provide unbiased decision in performance appraisal. This paper proposes a technique of reducing the vagueness, uncertainty and imprecision by collecting the precise data through the integration of timesheet for an individual. The paper describes the performance evaluation using the proposed system for an individual of an IT organization, considering the vertical as AMS (Application Management Service).
\end{abstract}

\section{General Terms}

Soft Computing, Artificial Neural Network.

\section{Keywords}

Performance, Appraisal, KRA, Timesheet, Performance Measures, KRA rules set, Weighted Rating, Artificial Neural Network.

\section{INTRODUCTION}

From an organizational point of view, there can be identified concepts of "measurement", "analysis", "assessment ", considering the idea that the performance can be defined as a state of competitiveness of the company, that can be reached by a level of efficiency and productivity that ensure a sustainable presence market" [1]. Employee evaluation is used to identify industrious employees and encourage meritocracy by promoting a system of compensation that is commensurate with performance [2]. Human resources with knowledge and competencies are the key assets in assisting firms and/or countries to sustain their competitive advantage. Globally competitive organizations will depend on the uniqueness of their human resources and the systems for managing human resources effectively to gain competitive advantages [3]. Generally employee evaluation includes measuring the things that make the most difference. The problem is that many of the things that make the most difference are not easily quantifiable [4]. The sort of parameters that can be considered includes attendance and punctuality, initiative, dependability, attitude, communication, productivity, interpersonal relationships, organizational and time management, knowledge sharing, safety, etc [5]. Employee evaluation should be fair and unbiased, since employee compensation is based on the results of performance appraisal [2].

\section{LITERATURE SURVEY}

\subsection{Existing Performance Appraisal Systems}

C.C. Yee and Y.Y. Chen proposed a performance appraisal system using multi-factorial evaluation model in dealing with appraisal grades which are often expressed vaguely in linguistic terms [6], [7]. The project was carried out in collaboration with one of the Information and Communication Technology Company in Malaysia with reference to its performance appraisal process [6]. Ming-Shin Kuo and GinShuh Liang presented a performance evaluation method for tackling fuzzy multi-criteria decision-making (MCDM) problems based on combining VIKOR and interval-valued fuzzy sets [8]. To illustrate the effectiveness of the method, a case study for evaluating the performances of three major intercity bus companies from an intercity public transport system is conducted. G Meenakshi proposed a Multi source feedback or 360-degree feedback based performance appraisal system using Fuzzy logic and implemented it in academics especially engineering colleges [4], [9]. The 360 degree appraisal system includes self-appraisal, superior's appraisal, subordinate's appraisal student's appraisal and peer's appraisal. Adam Golec and Esra Kahya presented a comprehensive hierarchical structure for selecting and evaluating a right employee [7], [10]. The process of matching an employee with a certain job is performed through a competency-based fuzzy model [4], [7].

Nisha Macwan and Priti Sajja proposed a neuro-fuzzy application to model the performance appraisal, which is based on the 3- layer Artificial Neural Network architecture. Aggregate values of fuzzy parameters are taken by ANN as input and weighted according to the values in the weight matrix, integrated in the hidden layer which is further modified by an activation function to give the outcome. The inputs are fed into the system through user interface and the output is the retention decision for the employee.

\subsection{Evaluation Parameters}

The existing evaluation methodology is based on multiple evaluation parameters [4]. The evaluation parameters can be objective or subjective [4], [9]. After reviewing evaluation criteria of various multinational companies and performance appraisal reports of different organizations evaluation parameters considered are: Attendance, Punctuality, Interpersonal Skills, Communication skills, Quality of work, Timely Delivery, Number of Escalations, Innovativeness, 
Team Collaboration, Job Knowledge, Number of Appreciations, Qualifications.

Each evaluation parameter is expressed using linguistic fuzzy scales. The evaluator gets an opportunity to consider evaluation parameters in form of intervals. In this case objectiveness can be associated with fuzzy scales of evaluation parameters by defining weights for each evaluation parameter [4], [9]. Moreover, the evaluation methodology considers different organizational levels i.e. Strategic, Tactical and Operational [4]. It is obvious that not all the parameters are equally important for the employees at different organizational levels hence weight matrix is defined for each evaluation parameter against the management level in the organization. Weight Matrix indicates the significance of particular parameter for an employee at a particular organizational level [4]

\section{PROPOSED SYSTEM}

The paper proposes a system to reduce the imperfection and vagueness of few of the above performance measures. The paper terms the performance measures as KRA- Key Performance Area. The proposed system is based on the reliability of the timesheet filled by the individual to account his/her daily activities [6].

\subsection{Timesheet}

A timesheet is a method for recording the amount of a time spent on each job. Customization of timesheet is required to gather the details for the performance measures. A timesheet can be used to store the micro details for the task which could then be used to get the integrated information for the particular task. A few of the micro details could include accounting the total hours allotted for the task/job, the type of task/job, number of appreciations/escalations over the job, Expected delivery of the job, Actual completion time of the job, number of defects raised over the job and individual involved in the job [6]. All timesheet data will be stored using $3 \mathrm{NF}$ to avoid redundancy of data, and improve the performance of the proposed system.

\subsection{Evaluation Parameters- KRAs}

The system Admin identify a set of KRAs which are currently being evaluated vaguely to form a vague weighted matrix for performance evaluation. Below are few KRAs that are considered for evaluation using the proposed system.

\subsubsection{Quality of Work:}

Quality of Work could be calculated by the number of defects obtained in the job. The more number of defects specifies the less quality of work. For multiple tasks, it is less efficient to comment on the quality of work parameter since some tasks could involve zero defects while some less defects.

\subsubsection{Timely Delivery:}

Timely delivery for the task involves the task to be completed and delivered out within the expected time.

\subsubsection{Team Collaboration:}

It involves participation in the team events and activities by an individual.

\subsubsection{Attendance:}

It represents the presence of an individual over duration. The punctuality for an individual could also be accounted in this KRA.

\subsubsection{Self Improvement or Trainings:}

It involves the continual improvement program for an individual. The advancement of technology requires the individuals to upgrade themselves to the latest techniques and be updated with the current knowledge.

\subsubsection{Customer Satisfaction and Escalations:}

The number of escalation and the number of appreciations may be accounted for the customer review for the work.

3.3 Ratings, Associated Scores and Rule set The system considers 5 different ratings- Outstanding, Above Expectations, Meets Expectations, Below Expectations and Poor hat can be assigned to the KRA's. We assign scores on a range 1-5 for the above ratings. The rules for selection of ratings needs to be defined which will help system to identify rating and associated score for the individual [6].

The Outstanding ratings gains the highest score and goes decreasing till the last rating specified. The data for the decision making for the ratings is obtained through the timesheet. We define the rules, in such a way that there would be distribution of the individual performances amongst all the ratings, and not concentrated to a specific rating. Also the system Admin defines them so that the most challenging rule gets the highest rating and the lease challenging is assigned the lowest rating score [6].

\subsection{Mathematical Model Using Set Theory}

Consider a system $\mathrm{S}$, which can be defined as,

S -"Calculating the performance score based on performance parameters."

Here, the system calculates score for each performance parameter based on the weight, rating and integrated timesheet data for respective parameter, and generates the total performance score based on the sum of individual scores for the parameter.

For this system $\mathrm{S}$, consider sets as,

$\mathrm{K}$-"Set of all performance parameters, expressed as KRAs."

W-"et of performance score for each KRA."

$\mathrm{R}$-"Set of Ratings for the KRAs."

So, initially system can be described as,

$\mathrm{K}-\mathrm{k} 1, \mathrm{k} 2, \ldots, \mathrm{kn}$

W - w1,w2,.,wn

$\mathrm{R}-\mathrm{r} 1, \mathrm{r} 2, ., \mathrm{rn}$

$K^{\prime}, W^{\prime}, R^{\prime}-$ NULL

Suppose, now the system initiates for the evaluation process. The system will first try to identify the first KRA and then obtain a rating based on rule set and integrated timesheet data. It will then calculate the KRA score based on the rating and weight for the KRA. Hence after the identification in first iteration the sets will be as follows:
$\mathrm{K}-\mathrm{k} 2, \mathrm{k} 3, ., \mathrm{kn}$
$\mathrm{W}-\mathrm{w} 2, \mathrm{w} 3, ., \mathrm{wn}$
$\mathrm{R}-\mathrm{r} 2, \mathrm{r} 3, . . \mathrm{rn} \mathrm{K} \mathrm{K}^{\prime}-\mathrm{k} 1$
$\mathrm{R}^{\prime}$ - r1 W' - w1 
Similarly the final state can be reached when K, W, R contains NULL and K', W', R' contains initial values of $\mathrm{K}, \mathrm{W}$, $\mathrm{R}$ respectively

The equation for evaluation value for an associate can be defined as-

$\mathrm{E}_{\mathrm{i}}=\sum_{k=1}^{n} W^{k} R^{k} / R^{m}$

Where, Ei is the evaluation score for associate $\mathrm{i}$.

$\mathrm{K}$ represents the number of KRA,

$W^{k}$ Represents the Weight for KRA k.

$R^{k}$ Represents the rating obtained by associate for KRA k.

$\mathrm{R}^{\mathrm{m}}$ Represents the maximum rating score.

\subsection{Mathematical Model Using Set Theory}

The system architecture is divided into three layers. The first layer consists of two modules- Timesheet portal and the Performance Appraisal Portal. The second layer consists of three services-Timesheet service, Authentication Service and Appraisal Service. The last layer consists of the database, which will store the task, timesheet, user and appraisal data. The data access layer will contain the LINQ to SQL.

\subsubsection{Timesheet portal:}

It will consist of User Login to authenticate the user. Upon successful login, the users can create tasks, fill and submit the timesheets.

\subsubsection{Performance Appraisal Portal:}

It will consist of User Login to authenticate the user. Upon successful login the users can configure the KRAs and generate the appraisal report.

\subsubsection{Timesheet service:}

The timesheet service will contain the service methods to create tasks, save the time sheet, and integrate the timesheet data.

\subsubsection{Authentication Service:}

The authentication service will authenticate the user during login.

\subsubsection{Appraisal Service:}

The appraisal service will contain service methods to save the configuration of the KRAs and generate appraisal report

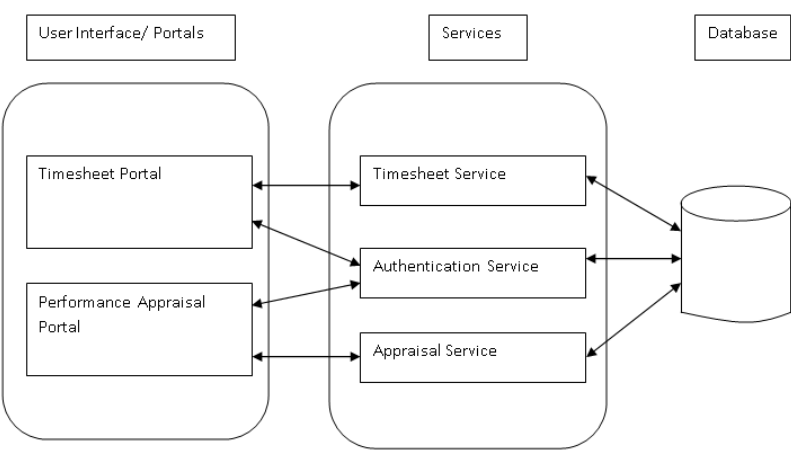

Fig 1: System Architecture

As shown in Fig. 2, the input data for performance appraisal is provided to the system. Considering KRA rating rule set, the ratings for each KRA for employee are obtained and are used to calculate the total performance score, a weight to be passed as input to the ANN system along with the current system knowledge. The hidden layer consists of the various models considered by the ANN system to decide on the output values. The System knowledge and the RMS values set are the part of the hidden layer. The output layer is the set of output values obtained by the system including the total performance score, Updated System Knowledge, Overall Performance Rating and the Retain Decision.



Fig 2: ANN Architecture

\subsection{Algorithm}

The proposed system uses the back-propagation method along with the following stochastic gradient descent algorithm to train the network-

\subsubsection{Stochastic gradient descent algorithm:}

Step 1- initialize network weights (often small random values) do

Step 2- forEach training example named ex

Step 3- prediction = neural-net-output(network, ex) // forward pass

Step $4-$ actual $=$ teacher-output $(e x)$

Step 5- compute error (prediction - actual) at the output units

Step 6- compute delta-maximum for all weights from hidden layer to output layer // backward pass

Step 7- compute delta-minimum for all weights from input layer to hidden layer // backward pass continued

Step 8- update network weights // input layer not modified by error estimate

until all examples classified correctly or another stopping criterion satisfied

Step 9- return the network

Once the network is trained, the following Algorithm is referenced to determine the ratings- 


\subsubsection{Proposed ANN algorithm:}

Step 1: Select the employee whose performance appraisal is to be conducted.

Step 2: The System integrates the data filled by an individual for the specified time period to generate the report for tasks.

i.e. for $\mathrm{t}=\mathrm{t} 1$ to $\mathrm{t} 2$, Generate $\mathrm{T}^{\prime}[\mathrm{i}]\left[\mathrm{t}^{\prime}\right]$ using $\mathrm{T}[\mathrm{i}][\mathrm{t}]$

Step 3: For each KRA, the system collects the data from the report required to set the rating for the KRA.

i.e. for each $\mathrm{k}$, Normalize data to calculate Rk.

Step 4: Based on the rules for the KRA, obtain the rating to be assigned and calculate the Total Performance Score for employee as-

Total Performance Score $(\mathrm{PS})=\operatorname{Sum}(\mathrm{w}(\mathrm{k}[\mathrm{i}]) * \mathrm{w}(\mathrm{r}[\mathrm{k}[\mathrm{i}]]))$ for $i=1$ to number of KRA

Step 5. Calculate the RMS Set by calculating RMS value for each rating as-

RMS Value $[\mathrm{r}]=\operatorname{Sqrt}(\mathrm{Sq}(\mathrm{PS}-\operatorname{Maximum}[\mathrm{r}])+\mathrm{Sq}(\mathrm{PS}-$ Minimum $[r])+S q(P S-M e a n[r]))$

Step 6. Determine the overall performance band as-

Overall performance band $(\mathrm{R})=\operatorname{Min}(\mathrm{RMS}[\mathrm{r} 1], \operatorname{RMS}[\mathrm{r} 2], \ldots .$. , RMS[rn])

Step 7. Update network weights.

Step 8. Perform decision on retention for the employee.

\section{RESULTS ANALYSIS}

\subsection{Experimental Analysis}

System Admin defines the following test criteria for the KRAs as shown in Table I, The ratings and the rule set for each rating for a KRA.

Table I. Test KRA Data

\begin{tabular}{|c|c|c|c|}
\hline KRA & $\begin{array}{l}\text { Rating } 1 \\
\text { (Excellent) }\end{array}$ & $\begin{array}{l}\text { Rating } 2 \\
\text { (Average) }\end{array}$ & $\begin{array}{l}\text { Rating } 3 \\
\text { (Poor) }\end{array}$ \\
\hline CSAT & More than 4 & $\begin{array}{ll}\text { Between } & 2 \\
\text { and } 4 & \end{array}$ & $\begin{array}{l}\text { Less than } \\
2\end{array}$ \\
\hline Escalations & 0 & Up to 2 & \\
\hline $\begin{array}{l}\text { Timely } \\
\text { Delivery } \\
\text { Percentage }\end{array}$ & 100 & Above 75 & $\begin{array}{l}\text { Less than } \\
75\end{array}$ \\
\hline $\begin{array}{l}\text { Number } \quad \text { Of } \\
\text { Defects }\end{array}$ & 0 & $\begin{array}{l}\text { Up to } 2 \text { per } \\
\text { task }\end{array}$ & $\begin{array}{l}\text { More than } \\
2 \text { per task }\end{array}$ \\
\hline $\begin{array}{l}\text { Technical } \\
\text { Training }\end{array}$ & 2 & 1 & 0 \\
\hline $\begin{array}{l}\text { Behavioral } \\
\text { Training }\end{array}$ & 2 & 1 & 0 \\
\hline Value Add & 2 & 1 & 0 \\
\hline
\end{tabular}

The system is then trained using training data for each rating. Training data considers the ideal ratings for the overall rating output in the training set to obtain the knowledge of ideal performance values each rating. Below is the training data for the system-
Table II. Training Data

\begin{tabular}{|c|c|c|}
\hline KRA & Input Rating & $\begin{array}{l}\text { Desired Overall } \\
\text { Rating }\end{array}$ \\
\hline CSAT & Excellent & \multirow{7}{*}{ Excellent } \\
\hline Escalations & Excellent & \\
\hline $\begin{array}{l}\text { Timely Delivery } \\
\text { Percentage }\end{array}$ & Excellent & \\
\hline Number Of Defects & Excellent & \\
\hline Technical Training & Excellent & \\
\hline $\begin{array}{l}\text { Behavioral } \\
\text { Training }\end{array}$ & Excellent & \\
\hline Value Add & Excellent & \\
\hline CSAT & Average & \multirow{7}{*}{ Average } \\
\hline Escalations & Average & \\
\hline $\begin{array}{l}\text { Timely Delivery } \\
\text { Percentage }\end{array}$ & Average & \\
\hline Number Of Defects & Average & \\
\hline Technical Training & Average & \\
\hline $\begin{array}{l}\text { Behavioral } \\
\text { Training }\end{array}$ & Average & \\
\hline Value Add & Average & \\
\hline CSAT & Poor & \multirow{7}{*}{ Poor } \\
\hline Escalations & Poor & \\
\hline $\begin{array}{l}\text { Timely Delivery } \\
\text { Percentage }\end{array}$ & Poor & \\
\hline Number Of Defects & Poor & \\
\hline Technical Training & Poor & \\
\hline $\begin{array}{l}\text { Behavioral } \\
\text { Training }\end{array}$ & Poor & \\
\hline Value Add & Poor & \\
\hline
\end{tabular}

Once the system training is completed for the ideal training data, following is the system knowledge obtained-

Table III. Network Knowledge

\begin{tabular}{|c|c|c|c|}
\hline Rating & Minimum & Mean & Maximum \\
\hline Excellent & 100 & 100 & 100 \\
\hline Average & 50 & 50 & 50 \\
\hline Poor & 25 & 25 & 25 \\
\hline
\end{tabular}

Now proceed to obtain results for the actual data. The actual data is obtained by the system using the timesheets filled by the user. The system will integrate the daily timesheet filled in by the user to obtain the report data in the desired format. For results analysis a Test Integrated format is defined to the system for an Employee in the Table IV. 
Table IV. Test Integrated Timesheet Data

\begin{tabular}{|l|c|}
\hline \multicolumn{1}{|c|}{ Parameter } & Value \\
\hline EmployeeID & Emp001 \\
\hline CSAT Rating & 4.2 \\
\hline Number Of Escalations & 1 \\
\hline $\begin{array}{l}\text { Number Of Defects Per } \\
\text { Task }\end{array}$ & 2 \\
\hline $\begin{array}{l}\text { Number Of Technical } \\
\text { Training }\end{array}$ & 1 \\
\hline $\begin{array}{l}\text { Number Of Behavioral } \\
\text { Training }\end{array}$ & 80 \\
\hline Timely Delivery Percentage & 0 \\
\hline Number Of Value Add & \\
\hline
\end{tabular}

Table V. System Calculated Results

\begin{tabular}{|l|c|}
\hline \multicolumn{1}{|c|}{ KRA } & Rating Obtained \\
\hline EmployeeID & Emp001 \\
\hline CSAT & Excellent \\
\hline Escalations & Excellent \\
\hline Number Of Defects & Average \\
\hline Technical Training & Excellent \\
\hline Behavioral Training & Average \\
\hline Timely Delivery & Average \\
\hline Value Add & Poor \\
\hline
\end{tabular}

Based on the test data in Table IV, now test the proposed system to obtain the KRA ratings for the employee referring to the KRA rule set. The ratings determined by the system can be represented as shown in Table $\mathrm{V}$. The ratings obtained in Table $\mathrm{V}$ can then be used by the proposed algorithm to determine the overall performance band for the employee.

When the above algorithm is applied to the results of Table V, obtain the Total Performance score as 90 and the following RMS set values-

Table VI. RMS set

\begin{tabular}{|l|c|}
\hline \multicolumn{1}{|c|}{ Rating } & RMS Value \\
\hline Excellent & 17.3205080756888 \\
\hline Average & 69.2820323027551 \\
\hline Poor & 112.583302491977 \\
\hline
\end{tabular}

Thus the Overall Performance Band is obtained as Excellent since the RMS value for Excellent is the minimum amongst the set.

The system knowledge is then updated using the details for employee and the updated system knowledge obtained is as follows-
Table VII. Updated System Knowledge

\begin{tabular}{|l|l|l|l|l|l|l|}
\hline Rating & $\begin{array}{l}\text { Prev. } \\
\text { Min. }\end{array}$ & $\begin{array}{l}\text { Prev. } \\
\text { Mean }\end{array}$ & $\begin{array}{l}\text { Prev. } \\
\text { Max. }\end{array}$ & $\begin{array}{l}\text { Rev. } \\
\text { Min. }\end{array}$ & $\begin{array}{l}\text { Rev. } \\
\text { Mean }\end{array}$ & $\begin{array}{l}\text { Rev. } \\
\text { Max. }\end{array}$ \\
\hline Excellent & 100 & 100 & 100 & 90 & 95 & 100 \\
\hline Average & 50 & 50 & 50 & - & - & - \\
\hline Poor & 25 & 25 & 25 & - & - & - \\
\hline
\end{tabular}

The updated system knowledge is then used for the calculation of results for the next employee.

To obtain the practical results, the system was implemented in one of the registered Software organization, A.M. Technologies Pvt. Ltd. The results analysis was done on a weekly basis to compare the accuracy of existing and proposed system. The results for accuracy over time as obtained from the organization can be shown as below-

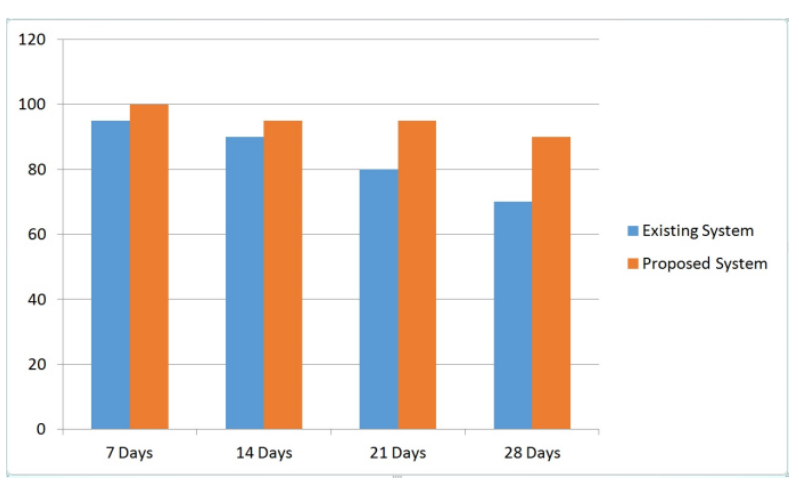

Fig 3: Accuracy vs. Time Results Analysis

As shown is Fig. 3, the accuracy of the existing system, decreases with the increase in time frame. The fall in accuracy of proposed system was found out to be dependent on the accuracy of the timesheet data. The accuracy of proposed system can be increased by implementing timesheet approval process, which includes introduction of an approval entity to verify and approve the timesheet data.

\subsection{Comparison of Existing and Proposed System}

\subsubsection{Timesheet based method for ratings} decision:

Since the performance appraisal for an individual is based on his work in the past duration of time, there are multiple tasks undertaken by the individual. Out of the numerous tasks, some tasks may be well performed while some may not. The decision to weight for these tasks in the existing system solely depends on the reviewer. Moreover sometimes, there might be a situation where in different sections in the organizations have a different view to assign the weights. Thus the existing system has the probability of imperfection while deciding the weights for the performance measures or the KRAs.

The proposed system has a centralized track of the organizations performance appraisal system. It has the ability to track the individual's performance for the task even after a long period of time. It has the ability to solely decide the weight for the KRA and does not change on account of any influences of the reviewer.

\subsubsection{Multiple output results:}

The existing system gives the final output as a retention decision. On the other hand the proposed system, involves the 
retention decision as well as the Total Performance score and Overall Performance band for the employee. The additional results in the proposed system, can be used for various purposes such as determining the promotion for the employee, or for determining the annual increments for the retained employees.

\subsubsection{Tracking Employee Performance over long duration:}

The existing system does not have the ability to track the employee performance over a long duration. The proposed system on the contrary can track the performance for the employee over any long period timeframe. It can thus be used to determine the growth for the employee in terms of performance and also analyze the performance trends for the employees.

Thus the proposed system can be considered as an approach to increase the effectiveness of the existing system.

\section{CONCLUSION}

After analysis of the existing systems for performance evaluation, it is found that there are some performance measures that are being calculated with vagueness and imperfection. To overcome this, the paper proposes a system that identifies few of the performance parameters, which could be tracked through the daily filled timesheet data. The paper proposes to integrate the daily timesheet data to provide the required data for performance appraisal of identified performance measures or the KRAs.

After experimental analysis, the researchers now look forward to implement the proposed system in various IT organizations and compare the feedback results in comparison to the existing system at more precise level. We also look forward to identify commonalities in the performance measures in various organizations to build a common performance evaluation system capable of making unbiased and precise decisions in performance appraisal.

\section{REFERENCES}

[1] Suzana Demyen, Ion Lala Popa, "Methods of determining the level of performance achieved by human resources in small and medium sized enterprises, using the analysis of specific indicators", Procedia - Social and Behavioral Sciences, pp. 43-50, 2014.

[2] A. Iyer, "Employee Evaluation Criteria", URL:http://www.buzzle.com/articles/employeeevaluation-cri teria.html, Retrieved on 29th Sep 2012

[3] V. Nagadevara, V. Srinivasan, \& R. Valk, "Establishing a Link between Employee Turnover and Withdrawal Behaviours: Application of Data Mining Techniques", Research and Practice in Human Resource Management, vol.16, no.1, pp.81-99, 2008.

[4] Nisha Macwan, Priti S. Sajja, (2014), “A Linguistic Fuzzy Approach for Employee Evaluation”, International Journal of Advanced Research in Computer Science and Software Engineering, Volume 4, no. 1, pp.975-980, January 2014.
[5] Ingrid Cliff, "How to conduct an Employee Appraisal: What criteria do you use to measure employee performance?", 2008.

[6] C.C. Yee, Y.Y.Chen, "Performance Appraisal System using Multifactorial Evaluation Model", World Academy of Science, Engineering and Technology 53, pp. 231$235,2009$.

[7] Nisha Macwan, Priti S. Sajja, (2013), "Performance Appraisal using Fuzzy Evaluation Methodology", International Journal of Engineering and Innovative Technology, Volume 3, no. 3, pp.324-329, September 2013.

[8] Ming-Shin Kuo, Gin-Shuh Liang, "A Soft Computing method of performance evaluation with MCDM based on interval-valued fuzzy numbers", Applied Soft Computing, vol. 12, no. 1, pp.476-485, 2012

[9] G Meenakshi, "Multi source feedback based performance appraisal system using Fuzzy logic decision support system", International Journal on Soft Computing ( IJSC ), vol.3, no.1, pp. 91-106, Feb. 2012.

[10] A. Golec, E. Kahya, "A fuzzy model for competency based employee evaluation and selection", Computers and Industrial Engineering, vol. 3, no.1,, pp. 143-161.

[11] Beer M, Spector B, Lawrence P, Mills DQ, Walton R, (1985), Human Resource Management: a general Managers Perspective, New York.

[12] Caldwell Cam, Truong Do, Linh Pham, Tuan Anh, (2011) Strategic Human Resource Management as Ethical Stewardship, Journal of Business Ethics, 98:171 182

[13] Ab. Aziz Yusof, Performance Appraisal Issues, Challenges \& Prospects, Pearson, 2003.

[14] G. Dessler, Human Resource Management, New Jersey, Pearson Education, Inc., 2000

[15] Guest David, Woodrow Christopher, (2012) Exploring the Boundaries of Human Resource Managers Responsibilities, Journal of Business Ethics, 109-119

[16] A. Voloshyn, G. Gnatienko, E. Drobot, "Fuzzy membership functions in a fuzzy decision making problem", International Journal "Information Theories \& Applications" Vol.10, 2003.

[17] ZHU Zhi-hong, XUE Da-wei. Fuzzy evaluation model of accounting firm knowledge management performance. Innovation Management and Industrial Engineering; 2009

[18] Nisha Macwan, Priti S. Sajja, (2013), "Modeling Performance Appraisal using Soft Computing Techniques: Designing Neuro-Fuzzy Application", International Conference on Intelligent Systems and Signal Processing (ISSP), pp.403--407, 2013. 